\title{
Synthesis of New Linear Polymers Containing Thiocarbonyl Groups: Polyaddition of Dicarbothioic Acid to Diolefins
}

\author{
Eiichi Kobayashi,* Kazuyoshi Tendo, Masato Kato, \\ and Sadahito Aoshima \\ Department of Industrial Chemistry, Faculty of Science and Technology, \\ Science University of Tokyo, Noda, \\ Chiba 278, Japan
}

(Received May 24, 1993)

\begin{abstract}
The polyaddition of 1,4-benzenedicarbothioic acid to 1,4-divinylbenzene or 1,4-diisopropenylbenzene was carried out at $70^{\circ} \mathrm{C}$ in toluene under a nitrogen atmosphere by radical mode such as by addition of AIBN or UV irradiation. Both diolefin compounds gave polymers in a $90 \%$ yield. The polymer obtained from 1,4-diisopropenylbenzene was soluble in chloroform, and the molecular weight of the polymer $\left(\bar{M}_{w}\right)$ was 40000 . On the other hand, the polymer obtained from 1,4-divinylbenzene was partly soluble in conventional organic solvents, possibly due to a cross linkage formation by a pendant vinyl group. The model addition reaction of thiobenzoic acid to styrene gave a by-product $c a$. $8 \%$ being the $1: 2$ adduct with respect to thiobenzoic acid and styrene. Alkali hydrolysis of both polymers was investigated to confirm the cross linkage structures in the polymers.
\end{abstract}

KEY WORDS Polyaddition / Polythioester / Addition Reaction / Hydrolysis / 1,4-Benzenedicarbothioic Acid / 1,4-Divinylbenzene / 1,4-Diisopropenylbenzene / Thiobenzoic Acid / Styrene / $\alpha$-Methylstyrene /

Addition reactions of carbothioic acids to olefins occur easily and are used to prepare various thioesters or polythioesters. For example, Ipatieff et al. ${ }^{1}$ and Crouch et al. ${ }^{2}$ synthesized thioesters by radical addition reaction of thioacetic acid to olefins. Marvel et al. reported the syntheses of various polythioesters by radical polyaddition of dicarbothioic acids to diolefins. ${ }^{3}$

Recently, the authors investigated the radical polyaddition of 1,4-benzenedithiol to 1,4divinylbenzene (DVB) as shown in eq $1 .{ }^{4,5} \mathrm{It}$ took place readily in solution under UV irradiation or in the presence of a radical initiator such as AIBN. The obtained polymer had a linear structure with high molecular weight $\left(\bar{M}_{w}=30000-100000\right)$. Interestingly, the polymer had a high refractive index
$\left(n_{\mathrm{D}}^{18}=1.81\right)$ and exhibited the reversible phase transition by heat mode.

$$
\begin{aligned}
\mathrm{CH}_{2}=\mathrm{CH} & -\mathrm{O}-\mathrm{CH}=\mathrm{CH}_{2}+\mathrm{HS}-\mathrm{O}-\mathrm{SH} \stackrel{\dot{\mathrm{R}} \text { or UV }}{\longrightarrow} \\
& +\mathrm{CH}_{2} \mathrm{CH}_{2}-(0) \mathrm{CH}_{2} \mathrm{CH}_{2} \mathrm{~S}-0-\mathrm{S} \mathrm{t}_{n}
\end{aligned}
$$

The authors synthesized new saturated polymers containing the thioester bond instead of the thioether bond. The introduction of carbonyl groups to the poly(thioethers) may increase intermolecular interactions between polymers. By variation of the intermolecular interactions, thermal properties, and liquid crystalline properties of the poly(thioethers) may be improved. Thus, 1,4-benzenedicarbothioic acid (BDTC) was polymerized with DVB or 1,4-diisopropenylbenzene (DIPB) to

* To whom all correspondence should be addressed. 
obtain new saturated polymers as shown in eq 2. The addition reaction of thiobenzoic acid (TBA) to styrene (St) or $\alpha$-methylstyrene (MSt) was also investigated as a model of the polyaddition of BDTC to DVB or DIPB. In addition, the hydrolysis of the obtained polymers was investigated in order to make clear their structures.

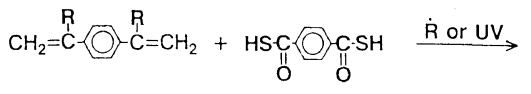

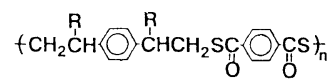

$$
\begin{aligned}
& \mathrm{R}=\mathrm{H}, \mathrm{CH}_{3}
\end{aligned}
$$

\section{EXPERIMENTAL}

\section{Reagents}

The authors applied the synthetic method of TBA $^{6}$ to the preparation of 1,4-benzenedicarbothioic acid (BDTC) (eq 3). In a suspension of $12.3 \mathrm{~g}(0.22 \mathrm{~mol})$ of sodium hy-

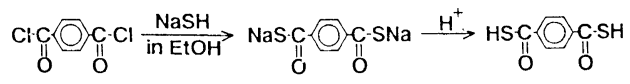

drosulfide (Nacalai Tesque Inc.) dried over conc. sulfuric acid in $80 \mathrm{ml}$ of anhydrous ethanol (Nacalai Tesque Inc.), a solution of $10.2 \mathrm{~g}(0.05 \mathrm{~mol})$ of terephthalyl chloride (Tokyo Chemical Industry Co.) in $100 \mathrm{ml}$ of anhydrous diethyl ether was added dropwise with stirring at $0-5^{\circ} \mathrm{C}$ under a nitrogen atmosphere. The reaction mixture was stirred at room temperature for $3 \mathrm{~h}$ to complete the reaction. $100 \mathrm{ml}$ of water were added in the reaction mixture to dissolve the product. The aqueous layer was washed five times with $50 \mathrm{ml}$ of diethyl ether to remove a trace amount of by-product, ethyl ester, and then $50 \mathrm{ml}$ of $6 \mathrm{~N}$ hydrochloric acid were added to the aqueous layer on an ice bath. The precipitate was recovered by filtration and washed with water until the $\mathrm{pH}$ was approx- imately 7. It was dried over anhydrous calcium chloride in vacuo at room temperature for about $12 \mathrm{~h}$. The product was purified by sublimation at $100^{\circ} \mathrm{C}$ under $0.1-0.05 \mathrm{mmHg}$. BDTC was obtained in a $96 \%$ yield as a yellow solid, mp $127.5-127.7^{\circ} \mathrm{C}$ (lit. ${ }^{7} 127.0-$ $127.5^{\circ} \mathrm{C}$ ). DVB was provided by Hokko Chemical Co. DIPB (Mitsui Petrochemical Co.), TBA (Tokyo Chemical Industry Co.), MSt (Nacalai Tesque Inc.), and St (Wako Pure Chemical Industries) obtained commercially were purified twice by vacuum distillation under a nitrogen atmosphere before use. Benzene and toluene (Nacalai Tesque Inc.) as reaction solvents were distilled over calcium hydride. 2,2'-Azobisisobutyronitrile (AIBN, Wako Pure Chemical Industries) was used as received. A nitrogen gas was purified as shown in the literature. ${ }^{8}$

For hydrolysis, tetrahydrofuran (THF, Nacalai Tesque Inc.), ethanol (Amakasu Chemical Industries), hydrochloric acid (Nacalai Tesque Inc.), chloroform (Nacalai Tesque Inc.), and ion-exchaged water were distilled to exclude oxygen under a nitrogen atmosphere before use. And powdery sodium hydroxide (Koso Chemical Industries) was heated at 150 ${ }^{\circ} \mathrm{C}$ in vacuo for $3 \mathrm{~h}$ to degas before use. Sodium tetrahydroborate (Kishida Chemical Co.) was used as received.

\section{Polyaddition}

Polyaddition was carried out in the presence of AIBN or with UV irradiation in toluene at $70^{\circ} \mathrm{C}$ under a nitrogen atmosphere as described in the previous papers. ${ }^{4,5}$ A typical example was as follows: in a pyrex tube equipped with a three-way stopcock, an equimolar amount of BDTC and DVB (1.1 mmol, each) in toluene $\left(13 \mathrm{ml}, 1.2 \times 10^{-1} \mathrm{~mol}\right)$ was charged by a medical syringe under a nitrogen atmosphere. The polymerization was initiated at $70^{\circ} \mathrm{C}$ by the addition of AIBN $\left(2.2 \times 10^{-2} \mathrm{mmol}\right)$ in toluene or with UV irradiation using a $450 \mathrm{~W}$ high pressure mercury lamp (Ushio Co.). The polymerization was terminated by pouring the 
polymerization mixture into a large amount of methanol, then the polymer precipitated was recovered by a centrifugation. After washing out residual monomers with methanol, the polymer was dried in vacuo at room temperature for $12 \mathrm{~h}$ over anhydrous calcium chloride.

\section{Model Addition Reaction}

The addition reaction of TBA $\left(1.0 \mathrm{moll}^{-1}\right)$ to St $\left(1.0 \mathrm{moll}^{-1}\right)$ or MSt $\left(1.0 \mathrm{moll}^{-1}\right)$ as a model of the polyaddition was carried out at $70^{\circ} \mathrm{C}$ in benzene by the addition of a benzene solution of AIBN $\left(1.0 \times 10^{-2}\right.$ or $5.0 \times 10^{-2}$ moll $\left.1^{-1}\right)$ under a nitrogen atmosphere similarly as below (see Figure captions for the reaction conditions such as the concentrations of the reagents). The course of the reaction was monitored by measurement of the concentrations of both monomers by GC using decane or trans-decalin as an internal reference. The addition product was obtained by removal of benzene from the reaction mixture without pretreatment.

\section{Hydrolysis}

The alkali hydrolysis of the polymers of BDTC-DVB $\left(4.9 \times 10^{-2}\right.$ repeating unit mol $\left.1^{-1}\right)$ and BDTC-DIPB $\left(4.9 \times 10^{-2}\right.$ repeating unit $\mathrm{moll}^{-1}$ ) was carried out at $40^{\circ} \mathrm{C}$ for $48 \mathrm{~h}$ in $0.76 \mathrm{~N}$ aqueous sodium hydroxideTHF-ethanol $(1: 1: 0.4)$ solution in the presence of sodium tetrahydroborate $(0.10 \mathrm{~mol}$ $1^{-1}$ ) under a nitrogen atmosphere. Since the produced thiols were oxidized easily, the reductive condition was maintained in the reaction system by the addition of sodium tetrahydroborate. After the reaction, to the reaction mixture $6 \mathrm{~N}$ hydrochloric acid was added on an ice bath until the solution became acidic.

The precipitate was recovered by filtration under a nitrogen atmosphere. A glass filter (G4) with ground joints was degassed by baking before use. The precipitate was washed with ion-exchaged water until the $\mathrm{pH}$ was approximately 7 , and then dried over anhy- drous calcium chloride in vacuo at room temperature for about $12 \mathrm{~h}$. Terephthalic acid was obtained as a white powder and its amount was determined by alkali titration.

The filtrate was extracted with three $15 \mathrm{ml}$ portions of chloroform under a nitrogen atmosphere. The chloroform layer was dried over anhydrous sodium sulfate at room temperature for about $12 \mathrm{~h}$. Thiols were obtained by evaporating the chloroform layer and their amounts were determined by GPC.

\section{Measurements}

${ }^{1} \mathrm{H}$ NMR spectra were obtained with a JEOL PMX-60si spectrometer and a JEOL JNMFX90Q spectrometer in $\mathrm{CDCl}_{3}$ with tetramethylsilane as an internal standard. IR spectra were recorded on a Hitachi $260-50$ spectrophotometer by the $\mathrm{KBr}$ method. Gel permeation chromatograms (GPC) were measured in chloroform on a Tosoh CCPD dual pump chromatograph with Tosoh TSKgel $\mathrm{GMH}_{\mathrm{XL}}$ column and JASCO Tri Rotar HPLC chromatograph with Shodex K-2002 column equipped with a UV/RI dual-mode detector. Sulfur contents of the polymers and adducts were determined by the modified Schoeniger's method. ${ }^{9,10}$ Gas chromatograms (GC) were made on a Shimadzu GC-4BMPF equipped with a flame ionization detector (FID) and Silicone GE SE-30 column $(2 \mathrm{~m})$ at $90^{\circ} \mathrm{C}$ under a nitrogen carrier gas $\left(37 \mathrm{ml} \mathrm{min}^{-1}\right)$. CI mass spectra were obtained with a JEOL JMSDX300.

\section{RESULTS AND DISCUSSION}

\section{Polyaddition of BDTC to DVB or DIPB}

The polyaddition of BDTC to DVB or DIPB was carried out in the presence of a conventional radical initiator AIBN or by UV irradiation in toluene at $70^{\circ} \mathrm{C}$ under a nitrogen atmosphere. In the case of the polyaddition of BDTC-DVB, the polymer gradually precipitated during reaction, while in the case of BDTC-DIPB, the reaction proceeded homo- 
Table I. Effects of initiation mode and polymerization time on the polyaddition of BDTC to DVB in toluene at $70^{\circ} \mathrm{C}$ under a nitrogen atmosphere ${ }^{a}$

\begin{tabular}{|c|c|c|c|c|c|}
\hline \multirow{2}{*}{ No. } & \multirow{2}{*}{$\begin{array}{c}\text { Initiation } \\
\text { mode }\end{array}$} & $\begin{array}{l}\text { Polymn } \\
\text { time }\end{array}$ & \multirow{2}{*}{$\frac{\text { Yield }}{\%}$} & \multirow{2}{*}{$\frac{S}{w t \%^{b}}$} & \multirow{2}{*}{$\begin{array}{c}\begin{array}{c}\text { Soluble } \\
\text { parts }\end{array} \\
\frac{\%^{c}}{}\end{array}$} \\
\hline & & $\mathrm{h}$ & & & \\
\hline 1 & None & 8 & 0 & - & - \\
\hline 2 & $\mathrm{AIBN}^{d}$ & 1 & 27 & 19.7 & 22 \\
\hline 3 & AIBN & 2 & 50 & 19.6 & 21 \\
\hline 4 & AIBN & 6 & 80 & 19.3 & $10^{\mathrm{e}}$ \\
\hline 5 & AIBN & 8 & 84 & 19.4 & 11 \\
\hline 6 & $U V^{f}$ & 1 & 80 & 19.5 & 10 . \\
\hline 7 & UV & 6 & 99 & 19.3 & 10 \\
\hline \multicolumn{6}{|c|}{$\begin{array}{l}\text { a }[\mathrm{BDTC}]_{0}=[\mathrm{DVB}]_{0}=8.5 \times 10^{-2} \mathrm{moll}^{-1} \text {. } \\
\text { b Schoeniger's method, calculated } \mathrm{S} \text { wt } \% \text { of } 1: 1 \\
\text { polymer is } 19.5 \text {. } \\
\text { c } 1 \mathrm{wt} \% \text { in } \mathrm{CHCl}_{3} \text { at room temp. time for } 24 \mathrm{~h} \text {. } \\
\text { d }[\mathrm{AIBN}]_{0}=1.7 \times 10^{-3} \text { moll } 1^{-1} \text {. } \\
\text { e mp was not observed up to the decomposition } \\
\text { temperature of } 300^{\circ} \mathrm{C} \text {. The molecular weight of the } \\
\text { polymer, even that of the soluble parts, exceeded } 10^{4} \text {, } \\
\text { the exclusion limit of the employed GPC column. } \\
\text { f } 450 \mathrm{~W} \text { high pressure mercury lamp. }\end{array}$} \\
\hline
\end{tabular}

geneously.

Table I shows the effects of the initiation mode and the polymerization time on the polyaddition of BDTC to DVB. The addition of AIBN and UV irradiation were effective to induce polyaddition, to give polymers in high yields ( 84 and $99 \%$ ). On the other hand, in the absence of an initiator no polymer was obtained. This indicates that the polyaddition proceeded by a radical chain mechanism. The obtained polymer was a white to pale-yellowish powder and partly soluble in chloroform. The value of sulfur content $(19.3-19.7 \%)$ was in fair agreement with the calculated value (19.5wt \% for the $1: 1$ polymer). In the IR spectrum of the polymer obtained by AIBN (Table I, No. 4), absorption peaks at $2500 \mathrm{~cm}^{-1}$ $(-\mathrm{SH})$ and $940 \mathrm{~cm}^{-1}\left(-\mathrm{CH}=\mathrm{CH}_{2}\right)$ due to each monomer disappeared, and new absorption peaks at $2900 \mathrm{~cm}^{-1}\left(-\mathrm{CH}_{2}-\right)$ and $755 \mathrm{~cm}^{-1}$ $\left(-\mathrm{CH}_{2} \mathrm{CH}_{2}-\right)$ appeared (Figure 1(a)). The absorption peak at $755 \mathrm{~cm}^{-1}$ was the character-

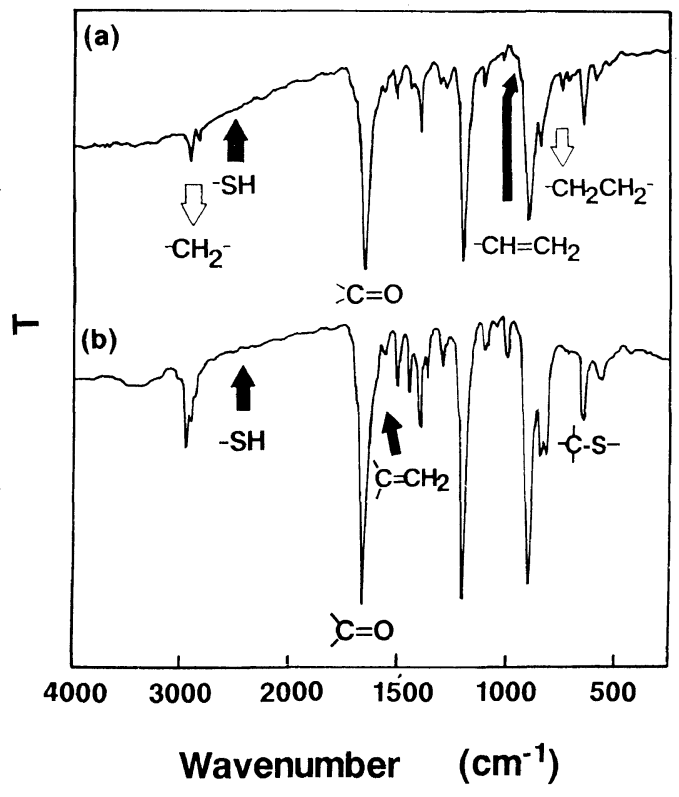

Figure 1. IR spectra of poly(BDTC-co-DVB) obtained by AIBN (Table I, No.4) (a) and poly(BDTC-DIPB) obtained by AIBN (Table II, No.11) (b) by the $\mathrm{KBr}$ method.

istic absorption of two methylene units $\left(-\mathrm{CH}_{2}\right)_{2}$. In the case of ethylene-propylene copolymers, the absorption of $752 \mathrm{~cm}^{-1}$ was assigned to $\left(\mathrm{CH}_{2}\right)_{2}$ sequence. ${ }^{11}$ The absorption peak of carbonyl group at $1660 \mathrm{~cm}^{-1}$ was also confirmed. The polymer structure was estimated from spectroscopic results $\left({ }^{1} \mathrm{H}\right.$ NMR and IR) for the model addition compound of TBA and St. The structure of the main addition product obtained in a $92 \%$ yield was $1: 1$ adduct (4) in Figure 7(a) of anti-Markownikoff's type (see the section of Model Addition Reaction). On the other hand, the ${ }^{1} \mathrm{H}$ NMR spectrum of the obtained polymer of BDTC and DVB could not be measured, because of lesser solubility, except for the soluble part in $\mathrm{CDCl}_{3}$, whose spectrum $[\delta, 7.2-8.0$ ppm (benzene ring, $8 \mathrm{H}$ ) and $2.7-3.4 \mathrm{ppm}$ $\left.\left(-\mathrm{CH}_{2} \mathrm{CH}_{2}-, 8 \mathrm{H}\right)\right]$ was similar to that of adduct (4) of TBA and St (Figure 7(a)). These results indicate that the obtained polymer has the anti-Markownikoff's structure (2). The expected reaction scheme is as follows: 


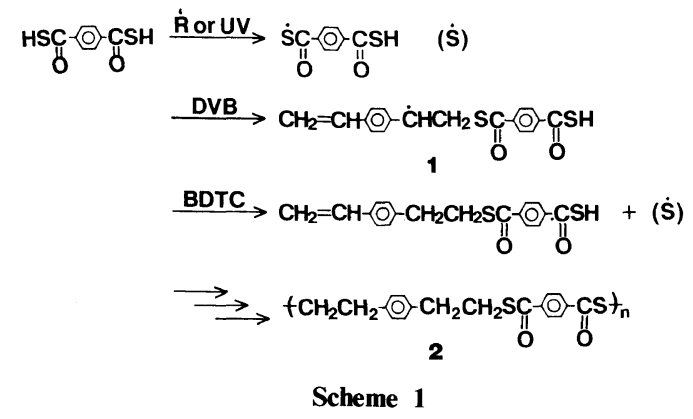

Table II. Effects of initiation mode and polymerization time on the polyaddition of BDTC to DIPB in toluene at $70^{\circ} \mathrm{C}$ under a nitrogen atmosphere ${ }^{a}$

\begin{tabular}{|c|c|c|c|c|c|}
\hline \multirow{2}{*}{ No. } & \multirow{2}{*}{$\begin{array}{l}\text { Initiation } \\
\text { mode }\end{array}$} & $\begin{array}{l}\text { Polymn } \\
\text { time }\end{array}$ & Yield & $S$ & \multirow{2}{*}{$\bar{M}_{w} \times 10^{-4^{c}}$} \\
\hline & & h & $\%$ & $w t^{0}{ }^{b}$ & \\
\hline 8 & None & 12 & 0 & - & - \\
\hline 9 & $\mathrm{AIBN}^{\mathrm{d}}$ & 5 & 31 & 18.0 & 0.3 \\
\hline 10 & AIBN & 10 & 57 & 18.0 & 1.0 \\
\hline 11 & AIBN & 60 & $87^{\mathrm{e}}$ & 17.8 & 1.7 \\
\hline 12 & $U^{f}$ & 2 & 55 & 17.9 & 1.0 \\
\hline 13 & UV & 3 & 85 & 17.8 & 2.0 \\
\hline 14 & UV & 5 & 90 & 17.8 & 4.0 \\
\hline
\end{tabular}

${ }^{\mathrm{a}}[\mathrm{BDTC}]_{0}=[\mathrm{DIPB}]_{0}=8.5 \times 10^{-2} \mathrm{moll}^{-1}$.

b Schoeniger's method, calculated $\mathrm{Swt} \%$ of $1: 1$ polymer is 18.0 .

c By GPC in $\mathrm{CHCl}_{3}$ (PSt calibration).

${ }^{d}[\mathrm{AIBN}]_{0}=8.5 \times 10^{-3} \mathrm{moll}^{-1}$.

e $T_{\mathrm{d}}$ (decomposition temperature) $\sim 300^{\circ} \mathrm{C} ; n_{\mathrm{D}}^{25}=1.70$ (calcd 1.75), measured by Duc de Chauless method with a polarized optical microscope.

f $450 \mathrm{~W}$ high pressure mercury lamp.

Table II shows the effects of the initiation mode and polymerization time on the polyaddition of BDTC to DIPB. The polyaddition proceeded faster by UV irradiation than by the addition of AIBN. The polymer was a white to pale-yellowish powder highly soluble in chloroform (1wt \%). The yield and the weight average molecular weight $\left(\bar{M}_{w}\right)$ are higher by UV irradiation than by AIBN. The polymer yield increased with time, and the molecular weight of polymers increased with polymer yield in either initiation mode (Figure 2 for UV irradiation, Figure 3 for addition of AIBN). It
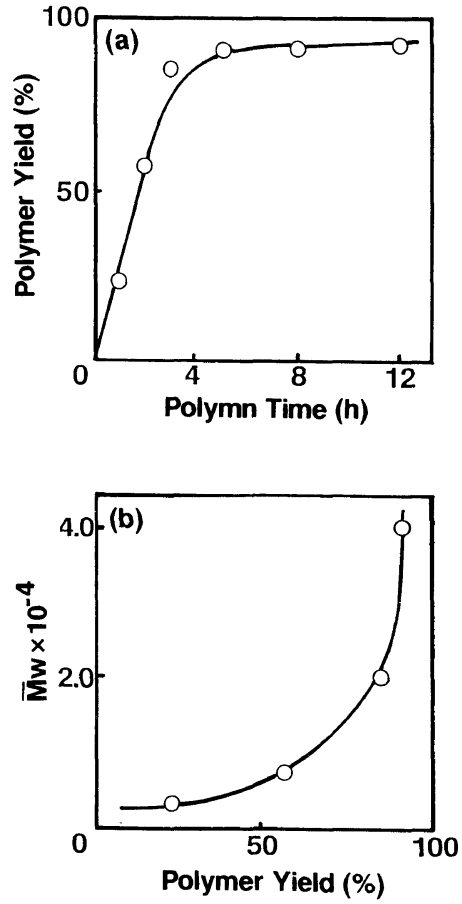

Figure 2. Relationship between polymerization time and polymer yield (a), and polymer yield and $\bar{M}_{w}$ (b) of poly(BDTC-co-DIPB) obtained by UV irradiation in toluene at $70^{\circ} \mathrm{C}$ under a nitrogen atmosphere. $[\mathrm{BDTC}]_{0}=$ $[\mathrm{DIPB}]_{0}=8.5 \times 10^{-2} \mathrm{moll}^{-1}$.

seems that the polyaddition proceeds in a stepwise type reaction; that is, the reaction between monomers occurs initially, then the reaction between oligomers and polymers occurs in the latter period. In ${ }^{1} \mathrm{H}$ NMR spectra of the BDTC-DIPB polymer obtained by AIBN (see Figure 4) and UV (Table II, No. 14), absorptions at $4.6 \mathrm{ppm}(-\mathrm{SH}), 4.8-5.3 \mathrm{ppm}$ $\left(=\mathrm{CH}_{2}\right)$, and $2.1 \mathrm{ppm}\left(-\mathrm{CH}_{3}\right)$ coming from each monomer disappeared and new absorptions at $\left.2.8-3.7 \mathrm{ppm}+\mathrm{CHCH}_{2}\right)$ and 1.0 $1.8 \mathrm{ppm}\left(-\mathrm{CH}_{3}\right)$ appeared. The proton ratios coincided with the calculated value for 3 . The sulfur content of polymers $(17.8-18.0 \%)$ is almost equal to that of the calculated value based on the $1: 1$ polymer $(18.0 \%)$. These results and IR spectrum as shown in Figure 1(b) all indicate that the obtained polymer has the anti-Markownikoff's structure 3. 

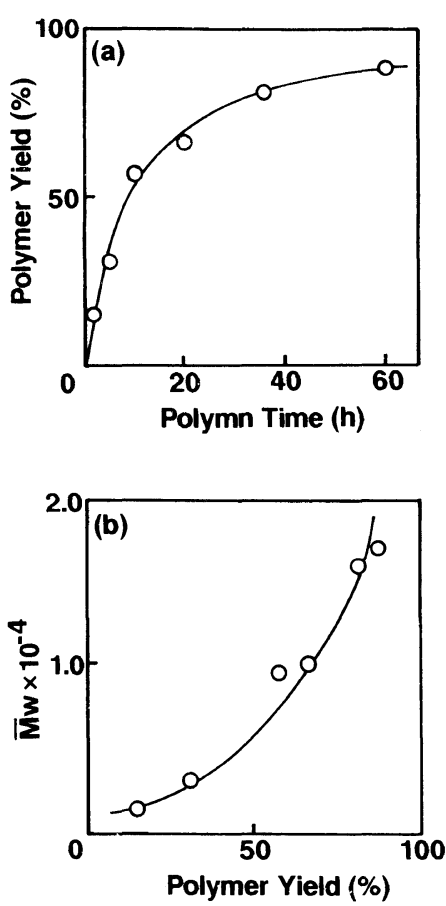

Figure 3. Relationship between polymerization time and polymer yield (a), and polymer yield and $\bar{M}_{w}$ (b) of poly(BDTC-co-DIPB) obtained by the addition of AIBN in toluene at $70^{\circ} \mathrm{C}$ under a nitrogen atmosphere. [BDTC $]_{0}=$ $[\mathrm{DIPB}]_{0}=8.5 \times 10^{-2} \mathrm{moll}^{-1} ;[\mathrm{AIBN}]_{0}=8.5 \times 10^{-3} \mathrm{~mol}$ $1^{-1}$.

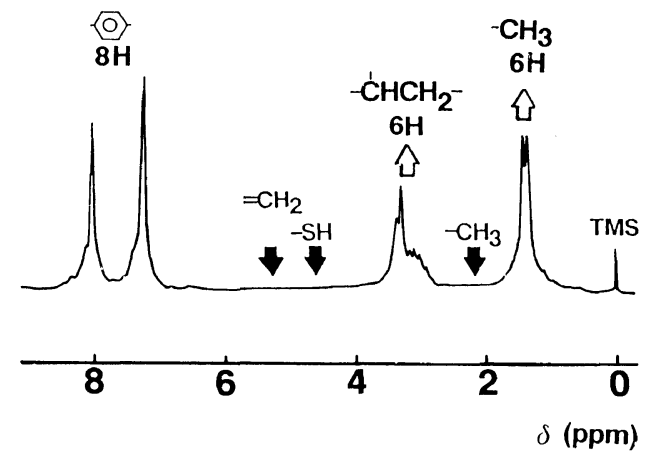

Figure 4. ${ }^{1} \mathrm{H}$ NMR spectrum $(90 \mathrm{MHz})$ of poly(BDTCco-DIPB) obtained by AIBN (Table II, No.11) in $\mathrm{CDCl}_{3}$.

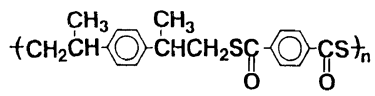

\section{Model Addition Reaction}

In the previous section, poor solubility of the BDTC-DVB polymer 2 in conventional organic solvents, compared with the BDTCDIPB polymer 3, was mentioned. The former polymer may have a cross linkage of the pendant vinyl group formed by the reaction between 1 in Scheme 1 and DVB, instead of the reaction with BDTC. The addition reaction of TBA to St or MSt was carried out as a model reaction of the polyaddition of BDTC to DVB or DIPB to investigate such a side reaction.

$\mathrm{TAB}$ was reacted with an equimolar amount of St with AIBN initiator in benzene at $70^{\circ} \mathrm{C}$. The addition reaction proceeded without an induction period, and both monomers disappeared for $6 \mathrm{~h}$, monitored by GC, as shown in Figure 5(a). The crude product was obtained by removal of benzene from the reaction mixture without pretreatment. The product obtained in a $92 \%$ yield was mainly the $1: 1$ adduct of TBA and St (4) in Figure 7, confirmed by GPC and ${ }^{1} \mathrm{H}$ NMR measurements (Figures 6(a) and 7(a)). The crude product contained ca. $8 \%$ oligomer (Figure 6(a)). The oligomer was estimated by ${ }^{1} \mathrm{H}$ NMR (Figure 7(b)) and IR spectra to be an adduct of TBA and two St units (5).

4: ${ }^{1} \mathrm{H}$ NMR, $87.2-8.0 \mathrm{ppm}$ (benzene ring, $10 \mathrm{H}), 2.7-3.4 \mathrm{ppm}\left(-\mathrm{CH}_{2} \mathrm{CH}_{2-}, 4 \mathrm{H}\right)$; IR, $2860 \mathrm{~cm}^{-1} \quad\left(-\mathrm{CH}_{2}-\right), \quad 1660 \mathrm{~cm}^{-1} \quad(; \mathrm{C}=\mathrm{O})$; $\mathrm{Swt} \%=13.3 \% \quad$ (calcd, 13.2\%); molecular weight, $\mathrm{MH}^{+}=243$ by mass spectroscopy, 250 by GPC (calcd, 242);

5: ${ }^{1} \mathrm{H}$ NMR, $\delta 7.1-8.0 \mathrm{ppm}$ (benzene ring, 15H), $2.0-3.8 \mathrm{ppm}\left(-\mathrm{CH}_{2} \mathrm{CH}_{2} \mathrm{CHCH}_{2}-, 7 \mathrm{H}\right)$; IR, $2860 \mathrm{~cm}^{-1}\left(\stackrel{\mathrm{C}}{\mathrm{C}} \mathrm{H}\right.$ and $\left.-\mathrm{CH}_{2}-\right), 1660 \mathrm{~cm}^{-1}$ $(=\mathrm{C}=\mathrm{O}) ; \mathrm{Swt} \%=9.1 \%$ (calcd, 9.3\%); molecular weight, $\mathrm{MH}^{+}=347$ by mass spectroscopy, 330 by GPC (calcd, 346).

In the case of MSt, the addition reaction of TBA to MSt by the addition of AIBN proceeded (Figure 5(b)) similarly to St. The product obtained in a $96 \%$ yield was mainly the $1: 1$ adduct of TBA and MSt (6) in Figure 
(a)

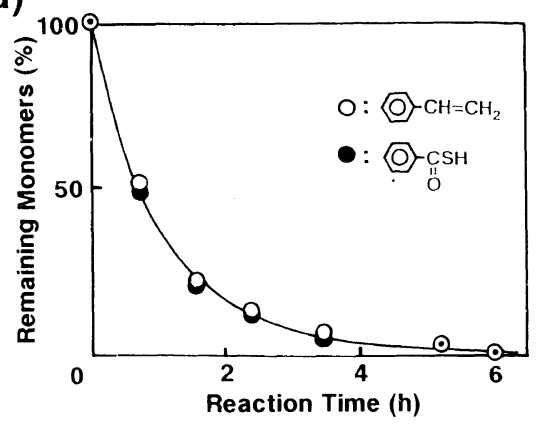

(b)

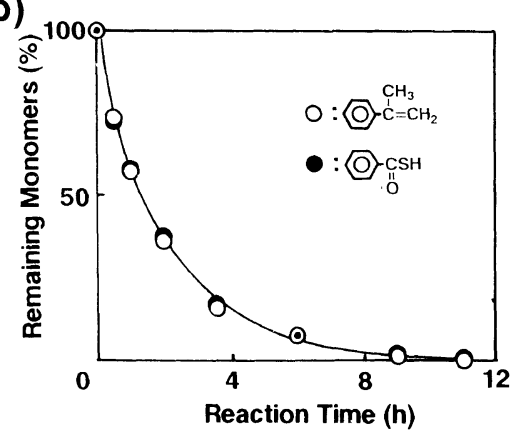

Figure 5. Relationship between reaction time and remaining monomers for the addition reaction of TBA to St (a) or MSt (b) in benzene at $70^{\circ} \mathrm{C}$ under a nitrogen atmosphere, monitored by GC. (a): $[\text { TBA }]_{0}=$ $[\mathrm{St}]_{0}=1.0 \mathrm{moll}^{-1} ;[\mathrm{AIBN}]_{0}=1.0 \times 10^{-2} \mathrm{moll}^{-1}$. (b): $[\mathrm{TBA}]_{0}=[\mathrm{MSt}]_{0}=1.0 \mathrm{moll}^{-1} ;[\mathrm{AIBN}]_{0}=5.0 \times$ $10^{-2} \mathrm{moll}^{-1}$.

(a)

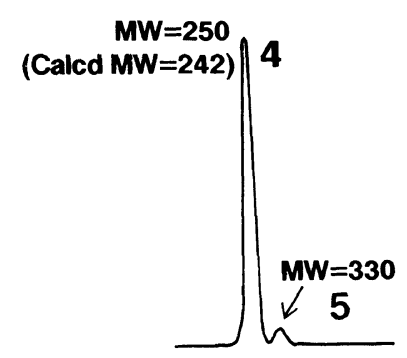

(b)

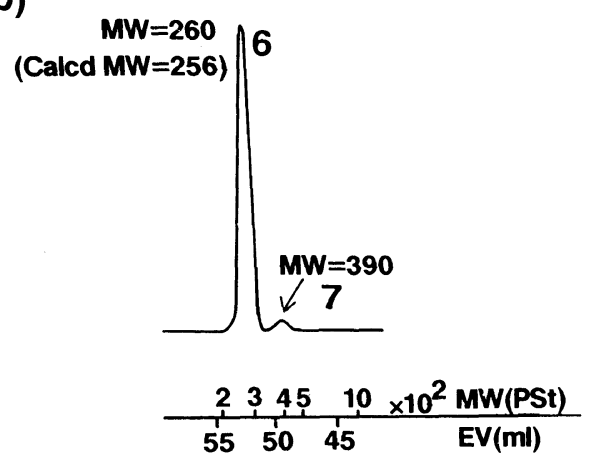

Figure 6. MWD curves of products obtained by the reaction of TBA and St in benzene at $70^{\circ} \mathrm{C}$ for $6 \mathrm{~h}(\mathrm{a})$, and TBA and MSt in benzene at $70^{\circ} \mathrm{C}$ for $11 \mathrm{~h}$ (b) under a nitrogen atmosphere. (a): $[\mathrm{TBA}]_{0}=[\mathrm{St}]_{0}=1.0 \mathrm{moll}^{-1}$; $[\mathrm{AIBN}]_{0}=1.0 \times 10^{-2} \mathrm{moll}^{-1}$. (b): $[\mathrm{TBA}]_{0}=[\mathrm{MSt}]_{0}=$ $1.0 \mathrm{moll}^{-1} ;[\mathrm{AIBN}]_{0}=5.0 \times 10^{-2} \mathrm{moll}^{-1}$.

8, confirmed by GPC and ${ }^{1} \mathrm{H}$ NMR measurements (Figures 6(b) and 8(a)). The crude product contained $c a .4 \%$ oligomer (Figure (a)

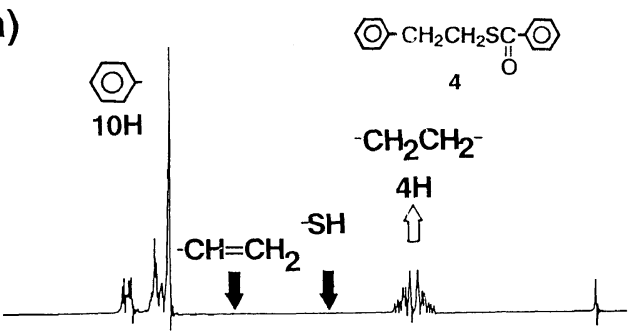

(b)

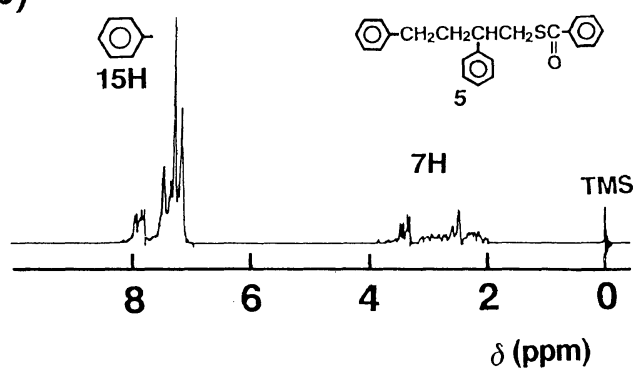

Figure 7. ${ }^{1} \mathrm{H}$ NMR spectra $(60 \mathrm{MHz})$ of main product (a) and by-product (b), fractionated by GPC (MW $=250$ and 330 in Figure. 6(a)), obtained by the reaction of TBA and $\mathrm{St}$ by AIBN in benzene at $70^{\circ} \mathrm{C}$ for $6 \mathrm{~h}$ under a nitrogen atmosphere. $[\mathrm{TBA}]_{0}=[\mathrm{St}]_{0}=1.0 \mathrm{moll}^{-1} ;[\mathrm{AIBN}]_{0}=$ $1.0 \times 10^{-2} \mathrm{~mol}^{-1}$. S wt \%: (a) $13.3 \%$ (calcd, $13.2 \%$ ); (b) $9.1 \%$ (calcd, 9.3\%). $\mathrm{MH}^{+}$: (a) 243 (calcd, 242); (b) 347 (calcd, 346).

6(b)), which was estimated to be an adduct of TBA and two MSt units (7) by ${ }^{1} \mathrm{H}$ NMR measurements (Figure 8(b)) similarly to the case of St. 
(a)

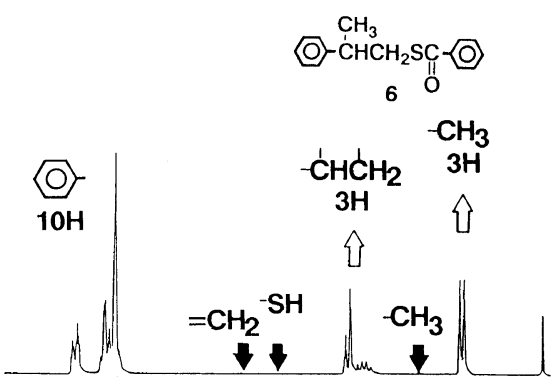

(b)

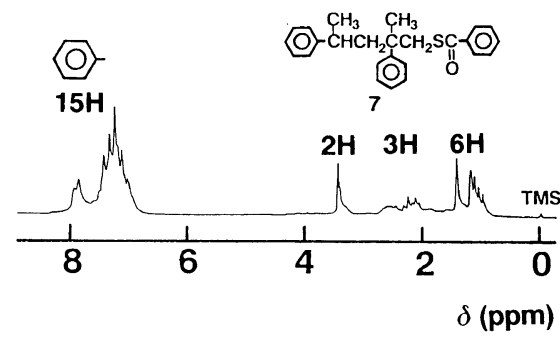

Figure 8. ${ }^{1} \mathrm{H}$ NMR spectra $(90 \mathrm{MHz})$ of main product (a) and by-product (b), fractionated by GPC (MW $=260$ and 390 in Figure 6(b)), obtained by the reaction of TBA and MSt by AIBN in benzene at $70^{\circ} \mathrm{C}$ for $11 \mathrm{~h}$ under a nitrogen atmosphere. $[\mathrm{TBA}]_{0}=[\mathrm{MSt}]_{0}=1.0 \mathrm{moll}^{-1}$; $[\mathrm{AIBN}]_{0}=5.0 \times 10^{-2} \mathrm{moll}^{-1}$. S wt \%: (a) $12.4 \%$ (calcd, $12.5 \%$ ); (b) $8.4 \%$ (calcd, $8.6 \%$ ). $\mathrm{MH}^{+}$: (a) 257 (calcd, 256); (b) 375 (calcd, 374).

6: ${ }^{1} \mathrm{H}$ NMR, $\delta 7.2-8.1 \mathrm{ppm}$ (benzene ring, 10H), 2.9-3.4 ppm (- $\left.\mathrm{CHCH}_{2}-, 3 \mathrm{H}\right), 1.3-1.5$ ppm $\left(-\mathrm{CH}_{3}, 3 \mathrm{H}\right) ; \mathrm{IR}, 1660 \mathrm{~cm}^{-1}(=\mathrm{C}=\mathrm{O}), 640$ $\mathrm{cm}^{-1}(\mathrm{C}-\mathrm{S}) ; \mathrm{Swt} \%=12.4 \%$ (calcd, $12.5 \%$ ); molecular weight, $\mathrm{MH}^{+}=257$ by mass spectroscopy, 260 by GPC (calcd, 256);

7: ${ }^{1} \mathrm{H}$ NMR, $\delta 6.8-8.1 \mathrm{ppm}$ (benzene ring, $15 \mathrm{H}), 3.4 \mathrm{ppm}\left(-{ }_{-}^{\mathrm{C}} \mathrm{CH}_{2} \mathrm{~S}-, 2 \mathrm{H}\right), 2.0-2.7 \mathrm{ppm}$ $\left(-\mathrm{CHCH}_{2} \stackrel{\mathrm{I}}{\mathrm{C}}-, 3 \mathrm{H}\right), 0.9-1.4 \mathrm{ppm}\left(-\mathrm{CH}_{3}, 6 \mathrm{H}\right)$; IR, $1660 \mathrm{~cm}^{-1} \quad(=\mathrm{C}=\mathrm{O}), 640 \mathrm{~cm}^{-1} \quad(\mathrm{C}-\mathrm{S})$; $\mathrm{S} w \mathrm{t} \%=8.4 \%$ (calcd, 8.6\%); molecular weight, $\mathrm{MH}^{+}=375$ by mass spectroscopy, 390 by GPC (calcd, 374).

Consequently, it was found that in each system the main addition product (92-96\% yield) had the anti-Markownikoff's type structure (4 or 6), and unexpectedly much byproducts ( $8 \%$ for TBA-St, $4 \%$ for TBA-MSt) were obtained. In the addition reaction of the $\mathrm{S}-\mathrm{H}$ bond of benzenethiol toward the vinyl group, the reactivity of St was 2.2 times lower than that of 1,4-divinylbenzene. ${ }^{8}$ The low reactivity of $\mathrm{St}$ may result in the production of much by-product as compared with the polymer. The reactivity of TBA toward St was also 4 times lower than that of benzenethiol. ${ }^{15}$ Accordingly, the amounts of by-products in the model addition reactions should be understood as increase in side reactions.

\section{Confirmation of Cross Linkage Structure in the} Polymers by Alkali Hydrolysis

The model addition reactions suggest that the $1: 2$ adduct of TAB and St or MSt exists as the by-product in the reaction mixtures. Thus, confirmation of a cross linkage structure in the polymers was made by alkali hydrolysis. Thioesters gave the corresponding thiols by the alkali or acid hydrolysis. ${ }^{12-14}$

Alkali hydrolysis of the polymers of BDTC-DVB and BDTC-DIPB was carried out at $40^{\circ} \mathrm{C}$ for $48 \mathrm{~h}$ in $0.76 \mathrm{~N}$ aqueous sodium hydroxide-THF-ethanol solution in the presence of sodium tetrahydroborate under a nitrogen atmosphere. Sodium hydroxide was added at about three times the molar quantity of the repeating unit. Figures 9(a) and (b) show the MWD curves of resulting thiol compounds by the alkali hydrolysis of polymers of BDTC-DIPB (Table II, No. 1.1) and BDTCDVB (Table I, No. 4) obtained by AIBN, respectively. In the former case, the main product obtained in a $99.7 \%$ yield was dithiol compound $\mathbf{8}$ from the regular polymer unit as shown in 3. A trace amount of by-product obtained in a $0.3 \%$ yield was the trithiol compound 9 from the cross linkage structure in the polymer chain.

8: ${ }^{1} \mathrm{H}$ NMR, $\delta 7.1 \mathrm{ppm}$ (benzene ring, $4 \mathrm{H}$ ), $2.4-3.2 \mathrm{ppm}\left(-\mathrm{CHCH}_{2}-, 6 \mathrm{H}\right), \quad 1.0-1.6 \mathrm{ppm}$ $\left(-\mathrm{CH}_{3}\right.$ and $\left.-\mathrm{SH}, 8 \mathrm{H}\right)$; IR, $2850-3070 \mathrm{~cm}^{-1}$ $(\mathrm{C}-\mathrm{H}), 2570 \mathrm{~cm}^{-1}(\mathrm{~S}-\mathrm{H}), 640 \mathrm{~cm}^{-1}(\mathrm{C}-\mathrm{S})$; $\mathrm{Swt} \%=28.2 \% \quad$ (calcd, 28.3\%); molecular 
(a) BDTC-DIPB AIBN

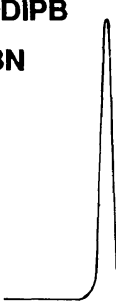

$M W=230$

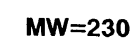

$($ Calcd $M W=418)$ (c) BDTC-DIPB

UV

$\mathrm{MW}=\mathbf{2 3 0}$

(Calcd MW=226)

$M W=460$

(Caicd MW=418) (b) BDTC-DVB

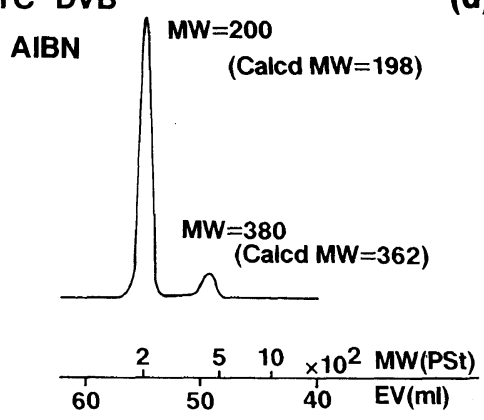

(d) BDTC-DVB

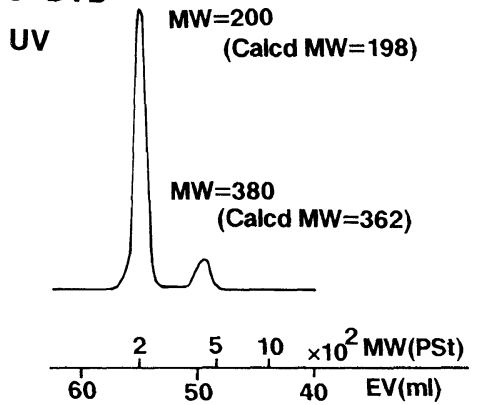

Figure 9. MWD curves of thiol products obtained by the alkali hydrolysis of poly(BDTC-co-DIPB) and poly(BDTC-co-DVB) $4.9 \times 10^{-2}$ repeating unit moll $1^{-1}$ in $0.76 \mathrm{~N}$ aqueous sodium hydroxideTHF-ethanol $(1: 1: 0.4)$ solution in the presence of sodium tetrahydroborate $\left(0.10 \mathrm{moll}^{-1}\right)$ at $40^{\circ} \mathrm{C}$ for $48 \mathrm{~h}$ under a nitrogen atmosphere. (a) poly(BDTC-co-DIPB) obtained by AIBN (Table II, No. 11); (b) poly(BDTC-co-DVB) obtained by AIBN (Table I, No. 4); (c) poly(BDTC-co-DIPB) obtained by UV irradiation (Table II, No. 13); (d) poly(BDTC-co-DVB) obtained by UV irradiation (Table I, No. 6).

weight, 230 by GPC (calcd, 226);

9: ${ }^{1} \mathrm{H}$ NMR, $\delta 6.9-7.2 \mathrm{ppm}$ (benzene ring, $8 \mathrm{H}), 1.9-3.1 \mathrm{ppm}\left(-\mathrm{CH}-\right.$ and $\left.-\mathrm{CH}_{2}-, 11 \mathrm{H}\right)$, $0.8-1.6 \mathrm{ppm} \quad\left(-\mathrm{CH}_{3}\right.$ and $\left.-\mathrm{SH}, 15 \mathrm{H}\right) ; \mathrm{IR}$, $2870-3070 \mathrm{~cm}^{-1}(\mathrm{C}-\mathrm{H}), 2570 \mathrm{~cm}^{-1}(\mathrm{~S}-\mathrm{H}), 640$ $\mathrm{cm}^{-1}(\mathrm{C}-\mathrm{S}) ; \mathrm{Swt} \%=22.8 \%$ (calcd, $23.0 \%$ ); molecular weight, 460 by GPC (calcd, 418).

$$
\begin{gathered}
\mathrm{HSCH}_{2} \mathrm{CH} \\
\mathbf{C}
\end{gathered}
$$

(S-H), $660 \mathrm{~cm}^{-1}(\mathrm{C}-\mathrm{S}) ; \mathrm{S} \mathrm{wt} \%=32.3 \%$ (calcd, $32.3 \%$ ); molecular weight, 200 by GPC (calcd, 198);

11: ${ }^{1} \mathrm{H}$ NMR, $\delta 7.0-7.3 \mathrm{ppm}$ (benzene ring, $8 \mathrm{H}), 1.8-3.1 \mathrm{ppm}\left(-\mathrm{CH}-\mathrm{H}-\mathrm{C}-\mathrm{CH}_{2}-, 15 \mathrm{H}\right)$, $1.1-1.6 \mathrm{ppm}$ (-SH, 3H); IR, $2850-3050 \mathrm{~cm}^{-1}$ $(\mathrm{C}-\mathrm{H}), 2570 \mathrm{~cm}^{-1}(\mathrm{~S}-\mathrm{H}), 660 \mathrm{~cm}^{-1}(\mathrm{C}-\mathrm{S})$; $\mathrm{Swt} \%=26.4 \% \quad$ (calcd, 26.5\%); molecular weight, 380 by GPC (calcd, 362).

$$
\begin{gathered}
\mathrm{HSCH}_{2} \mathrm{CH}_{2}(0) \mathrm{CH}_{2} \mathrm{CH}_{2} \mathrm{SH} \\
10
\end{gathered}
$$

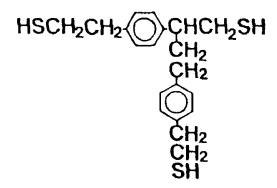

11 the diolefin, the yield of main dithiol compound (10) was $91.0 \%$, whereas that of trithiol compound (11) was $9.0 \%$.

10: ${ }^{1} \mathrm{H}$ NMR, $\delta 7.2 \mathrm{ppm}$ (benzene ring, $4 \mathrm{H}$ ), 2.5-3.1 ppm $\left(-\mathrm{CH}_{2}-, 8 \mathrm{H}\right), 1.2-1.6 \mathrm{ppm}(-\mathrm{SH}$, $2 \mathrm{H})$; IR, $2860-3050 \mathrm{~cm}^{-1}(\mathrm{C}-\mathrm{H}), 2570 \mathrm{~cm}^{-1}$ 
Table III Alkali hydrolysis of the BDTC-DIPB polymer and the BDTC-DVB polymer at $40^{\circ} \mathrm{C}$ for $48 \mathrm{~h}$ under a nitrogen atmosphere ${ }^{\mathrm{a}}$ and ratio of cross linkaged structure in the polymers

\begin{tabular}{|c|c|c|c|c|c|c|c|c|c|}
\hline \multirow{4}{*}{ No. } & \multicolumn{4}{|c|}{ Polymerization conditions } & \multirow{4}{*}{$\begin{array}{c}\begin{array}{c}\text { Recovery of } \\
\text { hydrolysis } \\
\text { products }^{b}\end{array} \\
\%\end{array}$} & \multirow{2}{*}{\multicolumn{3}{|c|}{$\begin{array}{l}\text { Mole of hydrolysis products } \\
\qquad\left(\times 10^{-4}, \mathrm{~mol}\right)\end{array}$}} & \multirow{4}{*}{$\begin{array}{c}\begin{array}{c}\text { Cross } \\
\text { linkage }\end{array} \\
\%\end{array}$} \\
\hline & \multirow{3}{*}{$\begin{array}{l}\text { Diolefin } \\
\text { monomer }\end{array}$} & \multirow{3}{*}{$\begin{array}{l}\text { Initiation } \\
\text { mode }\end{array}$} & \multirow{3}{*}{$\frac{\begin{array}{c}\text { Polymn } \\
\text { time }\end{array}}{\mathrm{h}}$} & \multirow{3}{*}{$\frac{\text { Yield }}{\%}$} & & & & & \\
\hline & & & & & & \multirow{2}{*}{8 or $10^{c}$} & \multirow{2}{*}{9 or $11^{c}$} & \multirow{2}{*}{$\mathrm{TA}^{\mathbf{d}}$} & \\
\hline & & & & & & & & & \\
\hline 15 & DIPB & AIBN & 60 & $87^{f}$ & 97 & 8.9 & 0.026 & 9.0 & 0.3 \\
\hline 16 & DVB & & 1 & $27^{g}$ & 96 & 8.0 & 0.42 & 8.7 & 5 \\
\hline 17 & DVB & & 6 & $80^{g}$ & 97 & 7.6 & 0.75 & 8.6 & 9 \\
\hline 18 & DIPB & UV & 3 & $85^{f}$ & 95 & 8.2 & 0.20 & 8.5 & 2 \\
\hline 19 & DVB & & 1 & $80^{\mathrm{g}}$ & 98 & 7.7 & 0.90 & 8.9 & 10 \\
\hline
\end{tabular}

${ }^{\mathrm{a}}[\text { Polymer }]_{0}=4.9 \times 10^{-2}$ repeating unit $\mathrm{moll}^{-1}$ in $0.76 \mathrm{~N}$ aquaous sodium hydroxide-THF-ethanol $(1: 1: 0.4)$ solution in the presence of sodium tetrahydroborate $\left(0.10 \mathrm{moll}^{-1}\right)$; polymer $=9.1 \times 10^{-4}$ repeating unit mol, which was assumed to be composed of the BDTC: DIPB (or DVB) $=1: 1$ structure as shown in eq 2 .

b By gravimetry. 'c By GPC. d TA, terephthalic acid, by titration.

e Calculated on the ratio of the resulting thiol compounds, $[9 /(8+9)] \times 100$ or $[11 /(10+11)] \times 100$.

f See Table II, No. 11 or No. 13.

g See Table I, No. 2, No. 4, or No. 6.

compounds and terephthalic acid were determined by GPC and titration, respectively (see EXPERIMENTAL). Recovery in this hydrolysis was $96-97 \%$ in each case. The percentage of cross linkage structure in the polymer chains was calculated from the amounts of the thiol compounds. The BDTC-DIPB polymer contained $0.3 \%$ of cross linkage structure, while BDTC-DVB polymer contained $5-9 \%$ of cross linkage structure. The percentage of cross linkage structure in the BDTC-DVB polymer was 15-30 times that in the BDTC-DIPB polymer. The reason for poor solubility of the BDTC-DVB polymer was elucidated as the cross linkage structure of the polymer. In the case of BDTC-DIPB polymer having $\bar{M}_{w}=$ 17000 , the polymer can be estimated to contain only 0.2 cross linkage points per polymer molecule from the calculation based on the results in Table III. Therefore, the BDTCDIPB polymer is highly soluble in chloroform. Further inspection of the BDTC-DVB polymer indicated that the polymerization time (or the yield) increased cross linkage points: $5 \%$ for $1 \mathrm{~h}$ (yield $27 \%$ ), $9 \%$ for $6 \mathrm{~h}$ (yield $80 \%$ ). It is also apparent that the cross linkage structure is already produced at the initial stage of polyaddition.

Figures 9(c) and (d) show the MWD curves of thiol compounds by the alkali hydrolysis of the polymers of BDTC-DIPB (Table II, No. 13) and BDTC-DVB (Table I, No. 6) obtained by UV irradiation. The yield of main dithiol compound from the regular polymer unit was 98\% (8) for BDTC-DIPB and $90 \%$ (10) for BDTC-DVB whose molecular weight was 230 (8) and 200 (10) by GPC (calcd, 226 and 198). The yields of the corresponding trithiol from cross linkage structure were 2 and $10 \%$, respectively, whose molecular weight was 460 (9) and 380 (11) by GPC (calcd, 418 and 362).

Table III (No. 18 and 19) shows moles of the hydrolysis products by alkali hydrolysis of the BDTC-DIPB and BDTC-DVB polymers obtained by UV irradiation. Recovery in this hydrolysis was 95 and $98 \%$. The BDTC-DIPB polymer contained $2 \%$ of the cross linkage structure, whereas $10 \%$ of the cross linkage structure was formed in the case of BDTCDVB. The ratios of cross linkage structure in 
the both polymers obtained by UV irradiation are larger than for the polymers obtained by AIBN. This indicates the facile formation of cross linkage structure in the polyaddition of BDTC to DVB or DIPB by UV irradiation.

According to a kinetic study, ${ }^{15}$ the rate determining step of this sort of addition reaction is the reaction between the intermediate carbon radical 1 in Scheme 1 and BDTC. However, the hydrogen transfer reactivity of thiocarboxylic acid is lower than that of thiol. In fact, the addition reaction of St and TBA gave relatively much by-product of TBA and two St units $(6 \%) .{ }^{15} 1$ may react with DVB prior to react with BDTC to form the pendant vinyl group. On the other hand, DIPB possesses an isopropenyl group similar to $\alpha$-methylstyrene. $\alpha$-Methylstyrene hardly polymerizes above the ceiling temperature ${ }^{16}$ as. $70^{\circ} \mathrm{C}$. This suppresses the formation of the pendant isopropenyl group.

Acknowledgment. The authors are indebted to Mr. T. Ohashi and Mr. M. Ozawa (Mitsubishi Petrochemical Co.) for measurement of the CI mass spectra.

\section{REFERENCES}

1. V. N. Ipatieff and B. S. Friedman, J.Am. Chem. Soc., 61, 71 (1939).

2. W. W. Crouch, P. T. Werkman, and R. J. Fanning, U. S. Patent, 2,626,279 (1953).

3. C. S. Marvel and A. Kotch, J. Am. Chem. Soc., 73, 1100 (1951).

4. T. Yagi, G. Morishita, and E. Kobayashi, Zairyo Gijyutsu, 7, 272 (1989).

5. E. Kobayashi, R. Kuribayashi, and S. Aoshima, submitted.

6. N. Rabjohn, "Organic Synthesis," Coll. Vol. iV, John Willy \& Sons, Inc., New York, N.Y., 1963, p 924.

7. C. S. Marvel and E. A. Kraiman, J. Org. Chem., 18, 707 (1953).

8. E. Kobayashi, T. Obata, S. Aoshima, and J. Furukawa, Polym. J., 22, 803 (1990).

9. W. Schoeniger, Mikrochim. Acta, 123 (1955).

10. W. Schoeniger, Mikrochim. Acta, 869 (1956).

11. G. Bucci and T. Simonazzi, J. Polym. Sci., C, 7, 203 (1964).

12. J. H. Chapman and L. N. Owen, J. Chem. Soc., 579 (1950).

13. S. Ogawara and Y. Sumitomo, Kogyokagaku Zasshi, 61, 1508 (1958).

14. E. N. Prilezhaeva, N. P. Petukhova, and M. F. Skostakovskii, Izv. Akad. Nauk. SSSR, Otd. Khim. Nauk, 728(1962), [Chem. Abstr., 57, 14930 (1962)].

15. E. Kobayashi, M. Sakakibara, T. Obata, S. Aoshima, and J. Furukawa, Polym. J., 25, 507 (1993).

16. J. Bandrup and E. H. Immergut, Ed., "Polymer Handbook," 2nd ed, Wiley, New York, N.Y., 1975, p II-437. 